\title{
Clinicopathological features and clinical efficacy of crizotinib in Chinese patients with $R O S 1$-positive non-small cell lung cancer
}

\author{
YOU-CAI ZHU ${ }^{1}$, XIN-GEN ZHANG ${ }^{2}$, XUE-PING LIN ${ }^{3}$, WEN-XIAN WANG ${ }^{4}$, XIAO-FENG LI ${ }^{1}$, \\ LI-XIN WU $^{1}$, HUA-FEI CHEN ${ }^{1}$, CHUN-WEI XU ${ }^{5}$ and KAI-QI DU ${ }^{1}$ \\ Departments of ${ }^{1}$ Thoracic Disease Center and ${ }^{2}$ Surgery, Zhejiang Rongjun Hospital; \\ ${ }^{3}$ Department of Pathology, Jiaxing University College of Medicine, Jiaxing, Zhejiang 314000; \\ ${ }^{4}$ Department of Chemotherapy, Zhejiang Cancer Hospital, Hangzhou, Zhejiang 310022; ${ }^{5}$ Department of Pathology, \\ Fujian Provincial Cancer Hospital, Fujian Medical University Cancer Hospital, Fuzhou, Fujian 350014, P.R. China
}

Received August 1, 2018; Accepted December 10, 2018

DOI: $10.3892 /$ ol.2019.9949

\begin{abstract}
C-ros oncogene 1 receptor tyrosine kinase (ROS1) rearrangement forms a novel molecular subgroup of non-small cell lung cancer (NSCLC). The present study explored the clinicopathological features and clinical efficacy of crizotinib in patients with ROS1-positive NSCLC. A retrospective analysis of 2,617 cases of NSCLC diagnosed between January 2013 and December 2016 was performed. ROS1 fusion genes were detected by reverse transcription-quantitative polymerase chain reaction, fluorescence in situ hybridization or next-generation sequencing techniques, and patients positive for the ROS1 fusion gene received oral treatment with crizotinib. The ROS1 fusion was identified in 67 out of 2,617 cases $(2.56 \%)$, including 21 cases that were male and 46 cases that were female. The median age was 68 years. Among these cases, $59(88.06 \%)$ were adenocarcinoma and 8 were non-adenocarcinoma. According to Tumor-Node-Metastasis (TNM) staging, 4 cases were stage I-IIIa and 63 (94.02\%) were stage IIIb-IV. The epidermal growth factor receptor (EGFR) gene status included 60 cases of wild-type, 1 case of co-mutation and 6 unknown cases. Statistically significant differences were identified for sex, TNM staging and EGFR gene status between ROS1 fusion gene-positive and -negative
\end{abstract}

Correspondence to: Professor Xin-Gen Zhang, Department of Surgery, Zhejiang Rongjun Hospital, 589 Central West Road, Jiaxing, Zhejiang 314000, P.R. China

E-mail: 1148534431@163.com

Abbreviations: NSCLC, non-small cell lung cancer; ROS1, C-ros oncogene 1 receptor tyrosine kinase; EGFR, epidermal growth factor receptor; KRAS, Kirsten rat sarcoma viral oncogene; ALK, anaplastic lymphoma kinase; RT-qPCR, reverse transcription-quantitative polymerase chain reaction; FISH, fluorescent in situ hybridization; NGS, next-generation sequencing; FFPE, formalin-fixed paraffin-embedded; ORR, objective response rate; DCR, disease control rate

Key words: lung neoplasms, clinicopathology, gene, treatment patients $(\mathrm{P}<0.001)$. A total of 23 patients received oral treatment with crizotinib, of which 13 (56.52\%), 5 (21.74\%) and $5(21.74 \%)$ patients demonstrated a partial response, stable disease and progressive disease, respectively. The objective response rate was $56.52 \%$ and the disease control rate was 78.26\%. Among all patients, the median progression-free survival (mPFS) time was 14.5 months. No differences were revealed in the mPFS time with regard to age, sex, smoking history, performance status score, histopathological type, TNM staging, tumor protein p53 gene status, EGFR gene status and first-line crizotinib treatment, whether by single or multiple factor analysis. The grade 3/4 treatment-associated adverse events included gastrointestinal disturbance, followed by increased transaminase concentration. In conclusion, the rate of ROS1 fusion in NSCLC among the patients is low, and crizotinib is an effective and safe drug for the treatment of ROS1-positive advanced NSCLC.

\section{Introduction}

Lung cancer is the leading cause of cancer-associated mortality in males and females in China. The majority of patients present with advanced non-small cell lung cancer (NSCLC) at the time of diagnosis. NSCLC may be categorized by the driving mutations identified in certain subtypes, including epidermal growth factor receptor (EGFR), Kirsten rat sarcoma viral oncogene $(K R A S)$ and anaplastic lymphoma kinase (ALK) mutations (1-4). Oncogenic ROS1 rearrangements have become one of the established molecular targets in lung cancer; however, they have only been identified in 1-2\% of NSCLC cases $(5,6)$. A total of 15 ROS1 fusion partner genes have been reported, including $\mathrm{H}-2$ class II histocompatibility antigen gamma chain (CD74), sodium-dependent phosphate transport protein 2B (SLC34A2), golgi-associated PDZ and coiled-coil motif-containing protein $(G O P C)$, coiled-coil domain-containing protein 6 (CCDC6), syndecan-4 (SDC4), tropomyosin alpha-3 chain (TPM3), ezrin (EZR), leucine-rich repeats and immunoglobulin-like domains protein 3 (LRIG3), ER lumen protein-retaining receptor 2 (KDELR2), LIM domain and actin-binding protein 1 (LIMA1), zinc finger protein MSN2 (MSN), clathrin heavy chain 1 (CLTC), tumor 
protein D53 (TPD52L1), L-amino-acid oxidase (FIG) and transmembrane protein 106B (TMEM106B) (7-9).

For patients with advanced NSCLC, chemotherapy and radiation provide only palliative relief, however, prognosis is poor for these patients. Molecular targeted therapy is effective for patients with advanced NSCLC with associated gene mutations. The EGFR tyrosine kinase inhibitors (TKIs), including geftinib, have been widely used as first-line treatments and have higher a sensitivity compared with platinum-based chemotherapy in advanced NSCLC with EGFR mutations (10). Crizotinib, an ALK inhibitor, was the first targeted agent approved by the US food and drug administration for the treatment of advanced ROS1-rearranged NSCLC, based on a series of trials $(11,12)$. These trials revealed that the objective response rate was $72 \%$, with a median progression-free survival (mPFS) time of 19.2 months. In addition, crizotinib demonstrated higher overall response and disease control rates and a longer progression-free survival (PFS) time in patients with NSCLC with ROS1 rearrangements, when compared with pemetrexed.

However, the majority of the aforementioned studies were performed among Caucasian populations. Therefore, the present study analyzed the clinicopathological features and clinical efficacy of crizotinib in Chinese patients with NSCLC and ROS1 rearrangement.

\section{Patients and methods}

Patients. A total of 2,617 patients diagnosed with NSCLC at Zhejiang Rongjun Hospital (Jiaxing, China), Zhejiang Cancer Hospital (Hangzhou, China) and Fujian Cancer Hospital (Fuzhou, China) between January 2013 and December 2016 were included in the current study (Fig. 1). The clinicopathological features of the patients are presented in Table I. The median age of all patients was 52 years (range, 22-92 years), including 1,415 males and 1,202 females. The inclusion criteria were as follows: i) Pathologically confirmed NSCLC with at least one measurable lesion; and ii) ROS1-positive cancer, as assessed by reverse transcription quantitative-polymerase chain reaction (RT-qPCR), fluorescence in situ hybridization (FISH) or next-generation sequencing (NGS) techniques. The exclusion criteria were as follows: i) ROS1-negetive cancer, and ii) patients who could not tolerate crizotinib therapy. The specimen types included fine-needle aspirate or bronchoscopic biopsy specimens (1,293 cases), surgical specimens (758 cases) and cytology specimens (566 cases). The patients' medical records were reviewed to evaluate clinicopathological features and treatment regimens. All clinical data included the patient's age, sex, smoking status, tumor histological type, performance status (PS), Tumor-Node-Metastasis (TNM) staging (13), EGFR gene status and previous treatment regimens. Non-smokers were defined as patients with a smoking dose of $<100$ cigarettes in their lifetime. The study was approved by the Ethics Committee of Zhejiang Rongjun Hospital (Jiaxing, China) and written informed consent was obtained from each participant.

Immunohistochemistry (IHC). The paraffin-embedded sections $(4 \mu \mathrm{m})$ were then dewaxed using grade I, II and III xylene for $5 \mathrm{~min}$. Subsequently, the sections were hydrated using $95 \%$ ethanol for $1 \mathrm{~min}$ followed by $80 \%$ ethanol for $1 \mathrm{~min}$, and washed with PBS three times for $1 \mathrm{~min}$ each time. Tissue samples were subjected to antigen retrieval in a microwave (600 W; Siemens AG, Munich, Germany) with 1 mM EDTA (pH 9.0; Fuzhou Maixin Biotech Co., Ltd., Fuzhou, China) four times for 5 min. ROS1 (D4D6) rabbit monoclonal antibody (catalog no. sc-3287; Cell Signaling Technology, Inc., Danvers, MA, USA) was applied at 1:150 in SigalStain antibody diluent (Cell Signaling Technology, Inc.) at room temperature for $1 \mathrm{~h}$. The sections were then incubated with $500 \mu \mathrm{g} / \mathrm{ml}$ normal goat IgG (catalog no. sc-2004; 1:3,000; DAKO; Agilent Technologies, Inc., Santa Clara, CA, USA) dissolved in $1 \%$ BSA in PBS ( $\mathrm{pH} 7.4$ ) for $1 \mathrm{~h}$ at room temperature. The sections were washed with PBS and then incubated with horseradish peroxidase (HRP)-conjugated goat anti-rabbit antibody (catalog no. 414162; Nichirei Corporation, Tokyo, Japan) in $1 \%$ BSA in PBS for $1 \mathrm{~h}$ at room temperature. Following washing with PBS, the sites of HRP were visualized with diaminobenzidine (DAB). As a negative control, certain sections were reacted with goat IgG. DAB or 3-amino-9-ethylcarbazole was used as the chromogen and slides were counterstained with haematoxylin for $2 \mathrm{~min}$ at room temperature prior to mounting. The color development was observed with a light microscope) (magnification, x200). ROS1 IHC was scored using the following scoring system: 0 , no staining; $1+$, faint cytoplasmic reactivity without any background staining; $2+$, moderate cytoplasmic reactivity; and $3+$, granular cytoplasmic reactivity of strong intensity in $10 \%$ of tumor cells.

$R T$-qPCR. Total RNA was extracted from three to four sections of 3- $\mu \mathrm{m}$ thick formalin-fixed paraffin-embedded (FFPE) tissues using an RNeasy FFPE kit (Qiagen $\mathrm{GmbH}$, Hilden, Germany). The ROS1 fusion was readily detected by PCR using a ROS1 fusion gene detection kit (Amoy Diagnostics Co., Ltd, Xiamen, China), according to the manufacturer's protocol. Briefly, total RNA was subjected to reverse transcription with a RT-PCR kit (catalog no. M1701, Promega Corperation, Madison, WI, USA) under the following conditions: $42^{\circ} \mathrm{C}$ for $1 \mathrm{~h}$ and $95^{\circ} \mathrm{C}$ for $5 \mathrm{~min}$. The resulting complementary DNA solutions were used in multiplex RT-qPCR to detect ROS1 fusion gene mRNA. For each case, four reactions were performed to amplify SLC34A2-ROS1, SDC4-ROS1, CD74-ROS1, EZR-ROS1, TPM3-ROS1, LRIG3-ROS1 and $G O P C-R O S 1$, and the reference gene HPRT1. All primers were included in the AmoyDx ${ }^{\circledR}$ ROS1 Gene Fusions Detection kit (AmonyDiagnostics Co., Ltd., Xiamen, China). All the assays were performed on an Agilent Mx3000P QPCR instrument (Agilent Technologies, Inc.). The following PCR procedure was used: An initial denaturation at $95^{\circ} \mathrm{C}$ for $5 \mathrm{~min}$, followed by $95^{\circ} \mathrm{C}$ for $25 \mathrm{sec}, 64^{\circ} \mathrm{C}$ for $20 \mathrm{sec}$ and $72^{\circ} \mathrm{C}$ for $20 \mathrm{sec}$ to ensure the specificity, and 31 cycles of $93^{\circ} \mathrm{C}$ for $25 \mathrm{sec}, 60^{\circ} \mathrm{C}$ for $35 \mathrm{sec}$ and $72^{\circ} \mathrm{C}$ for $20 \mathrm{sec}$ to perform the data collection. Quantification was achieved using the $2^{-\Delta \Delta \mathrm{Cq}}$ method (14) according to the fusion fluorescence signal. Assay reactions achieving $\mathrm{Cq}$ values of $<30$ cycles were considered positive. The housekeeping gene HPRT1 was used to control the integrity of the RNA. 
Table I. Clinical characteristics of patients.

Total patients $(n=2,617)$

Clinical characteristic ROS1-positive $(\mathrm{n}=67) \quad$ ROS1-negative $(\mathrm{n}=2,550)$

P-value ${ }^{\mathrm{a}}$

Crizotinib-treated $(n=23)$

Median age, years (range)

$68(35-79)$

$52(22-92)$

0.126

$64(35-79)$

Sex

Male

21

1,394

$<0.001$

Female

46

1,156

8

Smoking status

$46 \quad 1,156$

Yes

15

908

2

No

52

1,642

21

Stage

I-IIIa

4

809

1,741

0

IIIb-IV

63

\section{1,741}

2,009

541

59

8

Non-adenocarcinoma

Specimen type

Fine-needle aspirate or

bronchoscopy specimen

$\begin{array}{rr}46 & 1,247 \\ 4 & 754 \\ 17 & 549\end{array}$

$>0.999$

Surgical specimens

Cytology specimens

17

549

$60 \quad 941$

485

1,124

$<0.001$

0.066

23

EGFR status

Wild-type

1

6

14

0

9

$<0.001$

17

0

6

${ }^{\mathrm{a} C}$ Comparison between the clinical characteristics of ROS1 fusion-positive and -negative patients. ROS1, C-ros oncogene 1 receptor tyrosine kinase; EGFR, epidermal growth factor receptor.

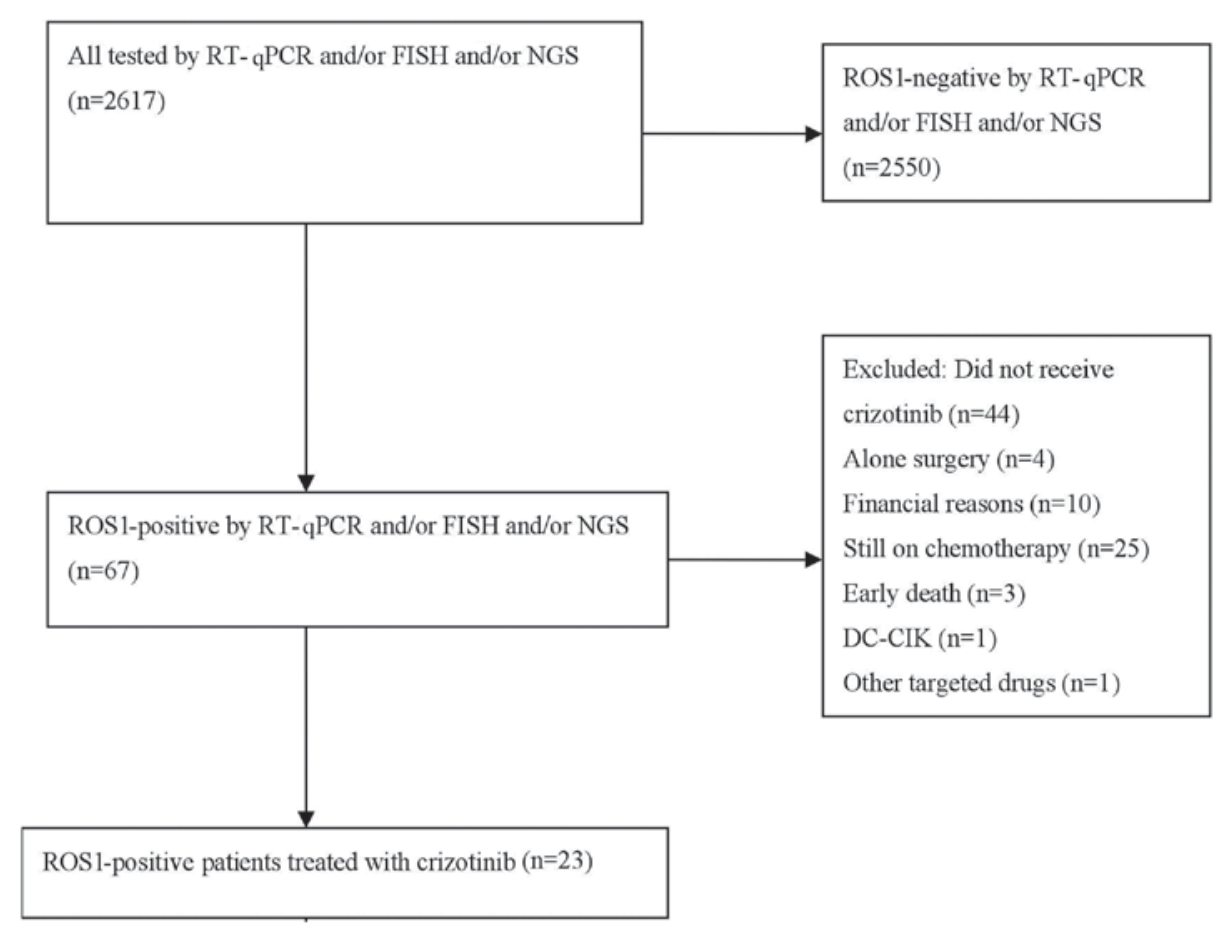

Figure 1. Study flow chart. RT-qPCR, reverse transcription-quantitative polymerase chain reaction; FISH, fluorescence in situ hybridization; NGS, next-generation sequencing; ROS1, C-ros oncogene 1 receptor tyrosine kinase; DC-CIK, dendritic cells- cytokine-induced killer cells. 


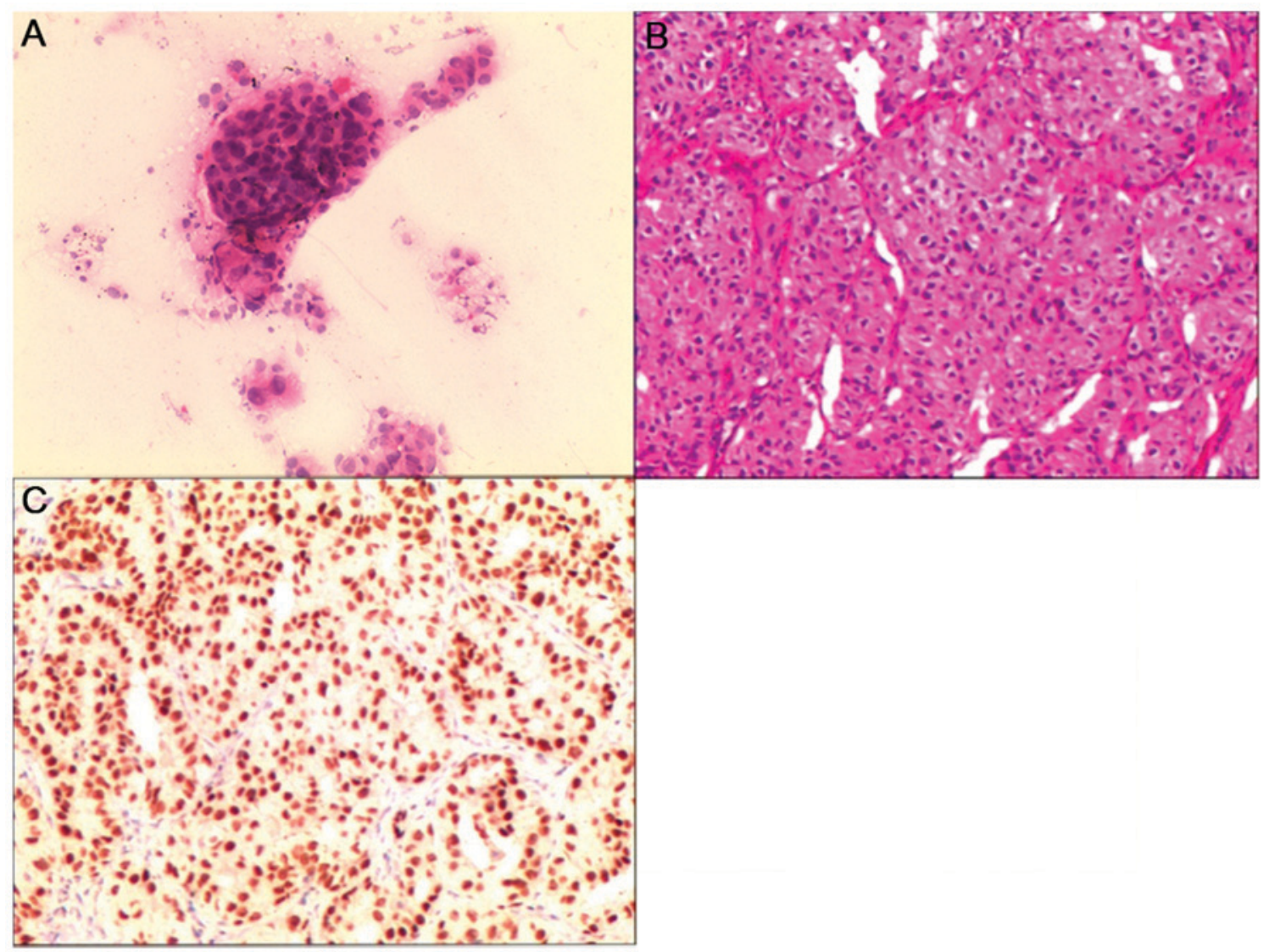

Figure 2. Histopathological staining. (A) Cytological smear revealing tumor cells of lung adenocarcinoma (magnification, x200). (B) Hematoxylin and eosin staining revealing lung adenocarcinoma tumor cells (magnification, x120). (C) Immunohistochemical staining revealing tumor cells positive for monoclonal anti-thyroid transcription factor-1 antibody (magnification, x100).

FISH. FISH analysis was performed on $3-\mu \mathrm{m}$ thick tissue microarrays with a break-apart probe specific to the ROSI locus (ZytoLight ${ }^{\circledR}$ SPEC ROS1 Dual Color Break Apart Probe; ZytoVision GmbH, Bremerhaven, Germany), according to the manufacturer's protocol. The slides were observed using a fluorescent microscope equipped with a digital camera (Shanghai Xinsheng Photoelectric Technology Co., Ltd., Shanghai, China). Tumor cells whose nuclei exhibited $\geq 1$ FISH signals of each color were enumerated. Cells positive for the rearrangement were defined as those with split signals or isolated green signals. A specimen was considered as ROS1-rearranged if the rearrangement-positive cells constituted $15 \%$ of the enumerated tumor cells.

NGS. Genomic DNA sequencing libraries were prepared using the protocols recommended by the Illumina TruSeq DNA Library Preparation kit (Illumina, Inc., San Diego, CA, USA). For samples close to the minimum input requirement, additional pre-capture PCR cycles were performed to generate sufficient PCR product for hybridization. The libraries were hybridized to custom-designed probes (Integrated DNA Technologies, Inc., Coralville, IA, USA), including all exons of 170 genes and selected introns of $A L K, R E T$ and ROS1, for the detection of genomic rearrangements. DNA sequencing was performed on a HiSeq3000 sequencing system (Illumina, Inc.) with $2 \times 75$ base pair paired-end reads. The reads were aligned to the human genome build GRCh37 using Burrows-Wheeler aligner (https://sourceforge.net/projects/bio-bwa/files/ bwa-0.7.15.tar.bz2/download). Somatic single nucleotide variant and indel calls were generated using MuTect (https://software.broadinstitute.org/gatk/documentation/version-history.php?id=7712\&page $=4$ ) and GATK version 3.0 (https://software.broadinstitute.org/gatk/documentation/version-history.php?id=7712\&page=4), respectively. Somatic copy number alterations were identified with CONTRA version 2.0.8 (https://sourceforge.net/projects/contra-cnv/files/). Genomic rearrangements were identified by software developed in-house for analyzing chimeric read pairs.

Evaluation of response. Patients received $250 \mathrm{mg}$ crizotinib twice daily and continued to receive therapy as long as they did not have progressive disease (PD) or intolerable side effects. The patients were evaluated for safety at least once every 2 weeks for the first two cycles and then at least every 4 weeks thereafter. Radiologic assessments were performed at baseline and generally following every two cycles of treatment. Additional assessment could be performed at any time when symptoms or signs suggested that the disease may be progressive. Clinical responses were evaluated according to the response evaluation criteria in solid tumors version 1.1 (15). PFS time was measured from the first day of treatment until either tumor progression or mortality from any cause. The last follow-up was on December 30, 2016. 


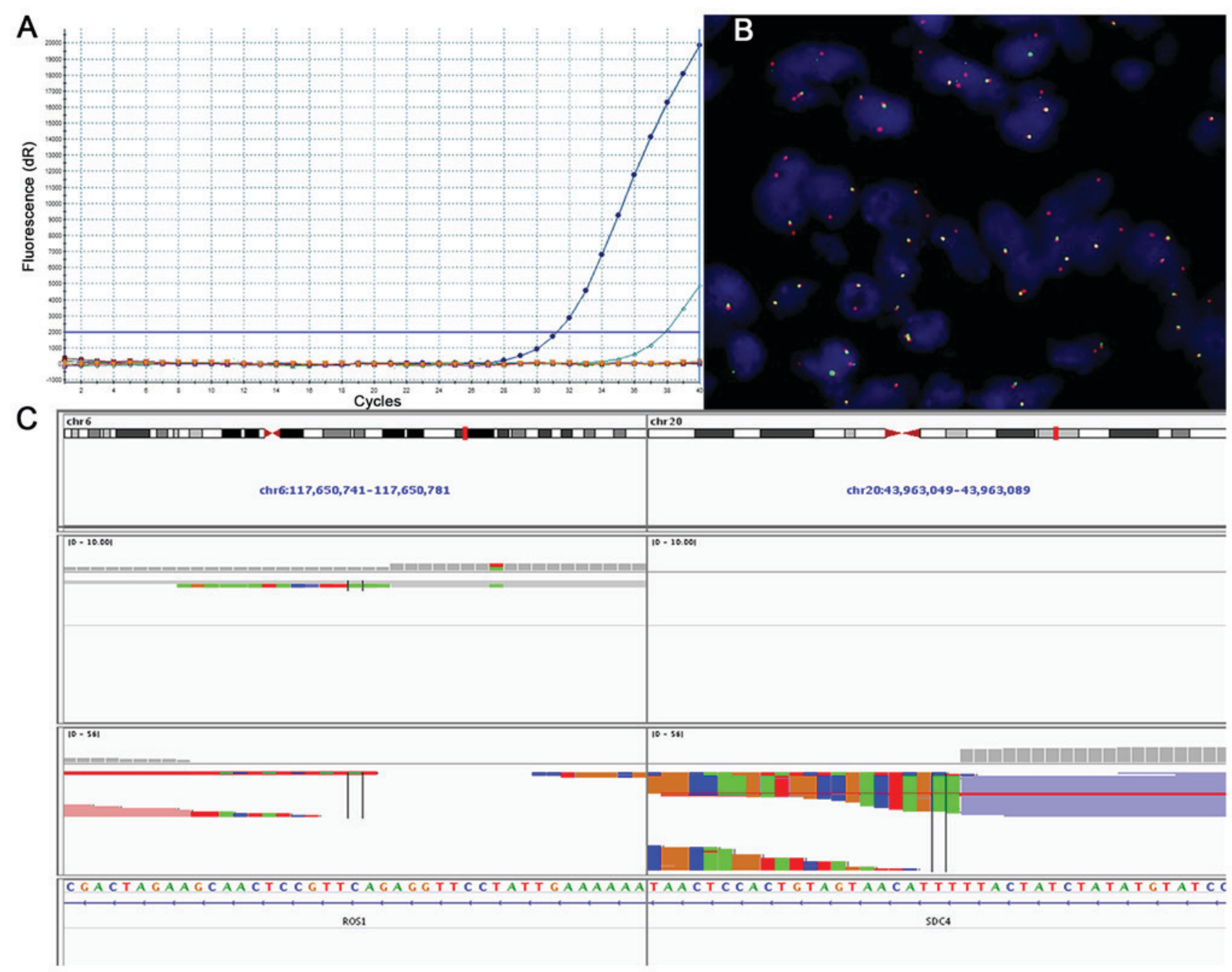

Figure 3. Detection of tumor cells with rearrangement of the ROS-1 gene by (A) reverse transcription-quantitative polymerase chain reaction, (B) fluorescence in situ hybridization (magnification, x1,000). (C) Next-generation sequencing. Chr, chromosome; ROS1, C-ros oncogene 1 receptor tyrosine kinase; SDC4, syndecan-4.

Statistical analysis. Categorical variables were compared using the $\chi^{2}$ test or Fisher's exact test when necessary. Survival curves were estimated using the Kaplan-Meier method and the log-rank test, with Bonferroni's correction applied for $>2$ groups. Statistical analysis was performed using SPSS version 19.0 software (IBM Corp., Armonk, NY, USA). All $\mathrm{P}$-values were two-sided and $\mathrm{P}<0.05$ was considered to indicate a statistically significant difference.

\section{Results}

Patient characteristics. The histopathological findings from different specimen types are demonstrated in Fig. 2. Results from tumors revealed to be ROSI-positive with the use of RT-qPCR, FISH or NGS are presented in Fig. 3. A total of 67 patients $(2.56 \%)$ were identified with ROS1 rearrangements, including 21 males and 46 females. The median age was 68 years. Among these cases, 59 (88.05\%) were adenocarcinoma and 8 were non-adenocarcinoma. According to the TNM staging, 4 cases were stage I-IIIa and 63 (94.03\%) were stage IIIb-IV. The EGFR gene status included 60 cases of wild-type, 1 case of co-mutation and 6 cases of unknown status. Statistically significant differences were identified with regard to sex, smoking history, TNM staging and EGFR gene status between ROS1 fusion gene-positive and -negative patients $(\mathrm{P}<0.05)$. No statistical significance was observed for age $(\mathrm{P}=0.126)$, histopathological type $(\mathrm{P}=0.066)$ or specimen type $(\mathrm{P}>0.999)$ between ROS1 fusion-positive and ROS1 fusion-negative patients. The clinicopathological features of the patients are outlined in Table I. A total of 23 patients with advanced NSCLC and a median age of 64 years (range, 35-79 years) received crizotinib, including 4 as first-line, 5, as second-line and 14 as third-line or later therapy.

Treatment response to crizotinib in patients with ROSI rearrangement. The tumor responses of patients who received crizotinib are presented in Table II. No patient exhibited a complete response, 13 achieved a partial response (Fig. 4), 5 exhibited stable disease and 5 presented with PD. The objective response rate (ORR) was $56.52 \%$ and the disease control rate (DCR) was $78.26 \%$. Among all cases, the median PFS time was 14.5 months (Fig. 5). To assess whether different factors could be used as predictive biomarkers of the median PFS time of patients treated with crizotinib, 
Table II. Efficacy of crizotinib in 23 cases of C-ros oncogene 1 receptor tyrosine kinase-positive non-small cell lung cancer.

\begin{tabular}{lccccccc}
\hline Response & CR, n & PR, n & SD, n & PD, n & ORR, \% & DCR, \% & mPFS, months \\
\hline Efficacy & 0 & 13 & 5 & 5 & 56.52 & 78.26 & 14.5 \\
\hline
\end{tabular}

$\mathrm{CR}$, complete response; $\mathrm{PR}$, partial response; $\mathrm{SD}$, stable disease; $\mathrm{PD}$, progressive disease; ORR, objective response rate; DCR, disease control rate; mPFS, median progression-free survival.

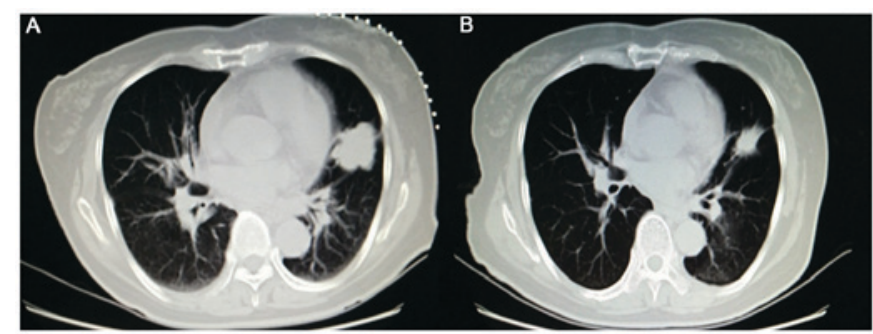

Figure 4. Computed tomography scan of a patient with C-ros oncogene 1 receptor tyrosine kinase fusion-positive non-small cell lung cancer (A) prior to and (B) following crizotinib treatment, demonstrating a good partial response.

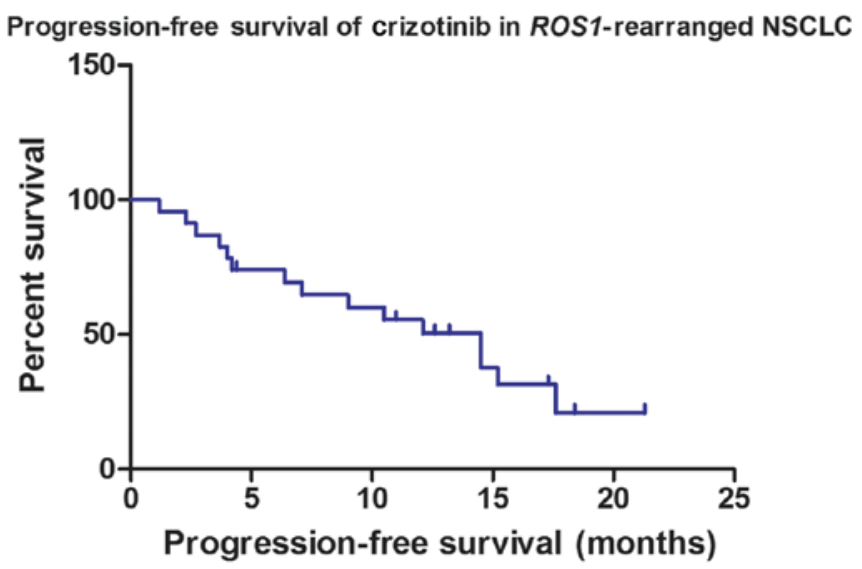

Figure 5. Progression-free survival of crizotinib in ROS1-rearranged NSCLC. ROS1, C-ros oncogene 1 receptor tyrosine kinase; NSCLC, non-small cell lung cancer.

single and multiple factor analyses were performed, including for age, sex, smoking history, PS score, pathology type, TNM staging, tumor protein p53 gene status, EGFR gene status and treatment line of crizotinib. Although EGFR status was significantly associated with median PFS time $(\mathrm{P}=0.038)$ in signal factor analysis (Table III), the results revealed no significant differences in median PFS time associated with these factors following multiple factor analysis (Tables III and IV).

The most common treatment-associated adverse events were of grades 1 and 2, including nausea, abdominal pain, diarrhea, visual disturbances, increased transaminase concentrations and skin rash. However, grade 3/4 gastrointestinal disturbance and increased levels of hepatic transaminases were observed in $4(17.39 \%)$ and $2(8.69 \%)$ patients who received crizotinib, respectively. Two patients stopped crizotinib
Table III. Single-factor analysis of the mPFS time of the patients.

\begin{tabular}{|c|c|c|c|c|}
\hline Clinical features & $\mathrm{n}$ & $\begin{array}{l}\text { mPFS, } \\
\text { months }\end{array}$ & $95 \% \mathrm{CI}$ & P-value \\
\hline Sex & & & & 0.386 \\
\hline Male & 8 & 14.5 & $8.3-20.7$ & \\
\hline Female & 15 & 10.5 & $0.1-20.9$ & \\
\hline PS & & & & 0.489 \\
\hline $0-1$ & 21 & 14.5 & $7.3-21.7$ & \\
\hline 2 & 2 & 6.4 & - & \\
\hline Age, years & & & & 0.426 \\
\hline$<60$ & 14 & 15.2 & 7.6-22.8 & \\
\hline$\geq 60$ & 9 & 10.5 & $2.5-18.6$ & \\
\hline Smoking history & & & & 0.191 \\
\hline Yes & 2 & 6.4 & - & \\
\hline No & 21 & 14.5 & $9.5-19.5$ & \\
\hline \multicolumn{5}{|l|}{ Pathology } \\
\hline Adenocarcinoma & 23 & 14.5 & $9.5-19.5$ & \\
\hline Non-adenocarcinoma & 0 & - & - & \\
\hline Crizotinib & & & & 0.106 \\
\hline First-line & 5 & 14.5 & $9.5-19.5$ & \\
\hline Second-line & 4 & 10.5 & $2.7-18.3$ & \\
\hline Third- or further-line & 14 & 3.7 & $0.0-9.9$ & \\
\hline \multicolumn{5}{|l|}{ TNM staging } \\
\hline I-IIIA & 0 & - & - & \\
\hline IIIB-IV & 23 & 14.5 & $9.5-19.5$ & \\
\hline$E G F R$ status & & & & 0.038 \\
\hline Mutation & 0 & - & - & \\
\hline Wild-type & 19 & 9.0 & $3.7-14.3$ & \\
\hline Unknown & 4 & - & - & \\
\hline TP53 status & & & & 0.254 \\
\hline Mutation & 2 & 4.2 & $1.0-7.4$ & \\
\hline Wild-type & 2 & 14.5 & - & \\
\hline Unknown & 19 & 14.5 & $9.5-19.5$ & \\
\hline
\end{tabular}

mPFS, median progression-free survival; $\mathrm{CI}$, confidence interval; PS, performance status; EGFR, epidermal growth factor receptor; TP53, tumor protein $\mathrm{p} 53$; TNM, Tumor-Node-Metastasis.

treatment for 3 days due to gastrointestinal disturbance. Patients with elevated transaminase levels were treated at a lower dose without recurrence of dose limiting toxic effects. 
Table IV. EGFR status analysis of the median progression-free survival time of the patients.

\begin{tabular}{lcccccr}
\hline Index & $\mathrm{B}$ & $\mathrm{SE}$ & Wald & P-value & RR & $95 \%$ CI \\
\hline EGFR status & -0.927 & 0.519 & 3.192 & 0.074 & 0.396 & $0.143-1.094$ \\
\hline
\end{tabular}

EGFR, epidermal growth factor receptor; CI, confidence interval; RR, relative risk; B, constant coefficient; SE, standard error.

\section{Discussion}

In 2007, it was first identified that ROS1 fusion genes are potential oncogenic drivers in NSCLC, as they were revealed in a rare subset of lung adenocarcinomas (16). ROS1 gene rearrangements were detected in $0.9-1.7 \%$ of unselected patients with NSCLC $(17,18)$. However, the frequency of ROS 1 fusions increased to $3 \%$ in lung adenocarcinoma and to $3.9-7.4 \%$ in patients with lung adenocarcinoma who possessed wild-type EGFR/KRAS/ALK (5,19-21). The frequency of ROS1 rearrangement was $2.56 \%$ among unselected patients with NSCLC in the current study, which was slightly higher compared with the results of previous studies. This may have been associated with the higher incidence of lung adenocarcinoma (79.02\%) in the present study.

Commonly, studies have demonstrated that ROS1 fusions are mutually exclusive with respect to $E G F R, K R A S$ mutations or $A L K$ fusions $(19,21)$. However, co-mutation of ROS1 with other driver genes has been reported in the literature (22-25). In these previous studies, 2 advanced NSCLC patients with concomitant ROS1 rearrangements and deletion of EGFR exon 19 presented with a partial response following first-line treatment with gefitinib. In addition, 1 patient with ALK/ROSI coexistence was treated with crizotinib for 3 months and responded to this inhibitor (26). However, KRAS oncogene point mutations may interfere with ROS1 signaling that is otherwise intact, resulting in a lack of response to crizotinib, and these are therefore associated with a poor ROS1-targeted therapy response (27). For patients with co-mutation ROS1-positive NSCLC, further studies are required to summarize the clinical presentation, different therapy regimens and prognostic factors.

Patients with EGFR mutations in Eastern Asia tend to be female, non-smokers and exhibit adenocarcinoma histology, on the basis of subgroup analysis (28). In addition, certain studies have demonstrated that patients with ROS1 rearrangements are often younger, non-smokers and exhibit adenocarcinoma histology $(20,29)$. However, other studies have reported contradictory findings $(19,30)$. The current results demonstrated that patients with ROS1 rearrangement were more frequently female with advanced-stage disease. Similar to EGFR-mutated NSCLC, differences have been revealed in clinicopathological features between Eastern Asian and Caucasian patients (31). For patients with ROS1-positive NSCLC, the biological features between different ethnicities require further research.

Although FISH has been approved for the detection of gene rearrangement in NSCLC, the high cost and complex operation limits its use $(5,32)$. Based on experience with $A L K$, assays for the detection of ROS1 have included FISH, RT-qPCR and NGS (33). These methods of detection each have their own advantages and disadvantages. In the current study, RT-qPCR was used for ROS1 fusion detection due to its high sensitivity, requirement for small samples and shorter detection time. NGS is a novel method for detecting large numbers of gene fusions with known and unknown genes, and gene mutations, at the same time (34).

Crizotinib has been demonstrated to be an effective drug in improving the prognosis of patients with NSCLC and ROS1 rearrangements. The objective response rate was previously identified to be $72 \%$ with an mPFS time of 19.2 months (11). A study reported that East Asian patients with ROS1 fusion who were treated with crizotinib demonstrated an ORR of $69.3 \%$ and an mPFS time of 13.4 months (35). In Chinese NSCLC patients with ROS1 rearrangements, crizotinib demonstrated a higher ORR (80.0\%) and DCR (90.0\%), and a longer PFS time (294 days) when compared with pemetrexed (30).

The current results demonstrated that crizotinib is effective against advanced NSCLC carrying activated ROS1 kinase. In 23 patients, the majority of whom had received multiple previous therapies, an ORR of $56.52 \%$ and DCR of $78.26 \%$ were observed. Among all cases, the mPFS time was 14.5 months. This response rate is high when compared with the response rate of $\sim 10 \%$ in such cancer cases treated with second-line chemotherapy. In addition, no associations were revealed between biological features and $\mathrm{MPFS}$ time.

However, similar to EGFR TKIs and $A L K$ TKIs, there is inevitable acquisition of resistance to targeted therapies. The acquired resistance mechanism for crizotinib in patients with NSCLC and ROS1 rearrangements is as yet unidentified. Molecular changes associated with this type of resistance in NSCLCs with ROS1 rearrangement are heterogeneous and include ROS1 tyrosine kinase mutations, EGFR activation and epithelial-to-mesenchymal transition (36).

In conclusion, the present study suggests that the rate of ROS1 fusion in Chinese patients with NSCLC is low. As an effective and safe drug, crizotinib may be use for treating patients with ROS1-positive advanced NSCLC. However, for this subtype, further studies are required to summarize the biological features and optimal treatments. Additionally, the current study had certain limitations. Firstly, it was a retrospective study, which may have allowed selection bias, and secondly, the number of patients treated with crizotinib was relatively small. Further large-scale studies are therefore required.

\section{Acknowledgements}

This abstract was presented at the IASLC 19th World Conference on Lung Cancer, 23-26 September 2018, in Toronto, Canada, and was published as P1.01-113 in J Thorac Oncol 13 (S508), 2018. 


\section{Funding}

This study was supported by the Science and Technology Planning Project of Zhejiang Province (grant no. 2015C33194), the Medical Scientific Research Foundation of Zhejiang Province (grant no. 2019RC027), the Technology Bureau of Jiaxing City (grant nos. 2016AY23087, 2017BY18050 and 2018AD32163) and the National Clinical Key Specialty Construction Program (grant no. 2013).

\section{Availability of data and materials}

The datasets used and/or analyzed during the present study are available from the corresponding author on reasonable request.

\section{Authors' contributions}

YCZ analysed and interpretated the data, drafted the manuscript, gave final approval of the version and agreed to be accountable for all aspects of the work. XGZ and WXW made substantial contributions to conception and design of the study. CWX and KQD obtained and analyzed the data. XPL, XFL, LXW and HFC performed the experiments. All authors read and approved the final manuscript.

\section{Ethical approval and consent to participate}

The present study was approved by the Ethics Committee of Zhejiang Rongjun Hospital (Jiaxing, China) and all participants provided written informed consent.

\section{Patient consent for publication}

Not applicable.

\section{Competing interests}

The authors declare that they have no competing interests.

\section{References}

1. Lynch TJ, Bell DW, Sordella R, Gurubhagavatula S Okimoto RA, Brannigan BW, Harris PL, Haserlat SM, Supko JG, Haluska FG, et al: Activating mutations in the epidermal growth factor receptor underlying responsiveness of non-small-cell lung cancer to gefitinib. N Engl J Med 350: 2129-2139, 2004.

2. Shi Y, Au JS, Thongprasert S, Srinivasan S, Tsai CM, Khoa MT, Heeroma K, Itoh Y, Cornelio G and Yang PC: A prospective, molecular epidemiology study of EGFR mutations in Asian patients with advanced non-small-cell lung cancer of adenocarcinoma histology (PIONEER). J Thorac Oncol 9: 154-162, 2014.

3. Lindeman NI, Cagle PT, Beasley MB, Chitale DA, Dacic S, Giaccone G, Jenkins RB, Kwiatkowski DJ, Saldivar JS, Squire J, et al: Molecular testing guideline for selection of lung cancer patients for EGFR and ALK tyrosine kinase inhibitors: Guideline from the College of American pathologists, international association for the study of lung cancer, and association for molecular pathology. J Thorac Oncol 8: 823-859, 2013.

4. Wood K, Hensing T, Malik R and Salgia R: Prognostic and predictive value in KRAS in non-small-cell lung cancer: A review. JAMA Oncol 2: 805-812, 2016.

5. Bergethon K, Shaw AT, Ou SH, Katayama R, Lovly CM, McDonald NT, Massion PP, Siwak-Tapp C, Gonzalez A, Fang R, et al: ROS1 rearrangements define a unique molecular class of lung cancers. J Clin Oncol 30: 863-870, 2012.
6. Davies KD, Le AT, Theodoro MF, Skokan MC, Aisner DL, Berge EM, Terracciano LM, Cappuzzo F, Incarbone M, Roncalli M, et al: Identifying and targeting ROS1 gene fusions in non-small cell lung cancer. Clin Cancer Res 18: 4570-4579, 2012.

7. Cancer Genome Atlas Research Network: Comprehensive molecular profiling of lung adenocarcinoma. Nature 511: 543-550, 2014

8. Ou SH, Chalmers ZR, Azada MC, Ross JS, Stephens PJ, Ali SM and Miller VA: Identification of a novel TMEM106B-ROS1 fusion variant in lung adenocarcinoma by comprehensive genomic profiling. Lung Cancer 88: 352-354, 2015.

9. Zhu VW, Upadhyay D, Schrock AB, Gowen K, Ali SM and Ou SH: TPD52L1-ROS1, a new ROS1 fusion variant in lung adenosquamous cell carcinoma identified by comprehensive genomic profiling. Lung Cancer 97: 48-50, 2016.

10. Maemondo M, Inoue A, Kobayashi K, Sugawara S, Oizumi S, Isobe H, Gemma A, Harada M, Yoshizawa H, Kinoshita I, et al: Geftinib or chemotherapy for non-small-cell lung cancer with mutated EGFR. N Engl J Med 362: 2380-2388, 2010.

11. Shaw AT, Ou SH, Bang YJ, Camidge DR, Solomon BJ, Salgia R, Riely GJ, Varella-Garcia M, Shapiro GI, Costa DB, et al: Crizotinib in ROS1-rearranged non-small-cell lung cancer. N Engl J Med 371: 1963-1971, 2014.

12. Mazières J, Zalcman G, Crinò L, Biondani P, Barlesi F, Filleron T, Dingemans AM, Léna H, Monnet I, Rothschild SI, et al: Crizotinib therapy for advanced lung adenocarcinoma and a ROS1 rearrangement: Results from the EUROS1 cohort. J Clin Oncol 33: 992-999, 2015.

13. Chansky K, Detterbeck FC, Nicholson AG, Rusch VW, Vallières E, Groome P, Kennedy C, Krasnik M, Peake M, Shemanski L, et al: The IASLC lung cancer staging project: External validation of the revision of the TNM stage groupings in the eighth edition of the TNM classification of lung cancer. J Thorac Oncol 12: 1109-1121, 2017.

14. Livak KJ and Schmittgen TD: Analysis of relative gene expression data using real-time quantitative PCR and the 2(-Delta Delta C(T)) method. Methods 25: 402-408, 2001.

15. Eisenhauer EA, Therasse P, Bogaerts J, Schwartz LH, Sargent D, Ford R, Dancey J, Arbuck S, Gwyther S, Mooney $\mathrm{M}$, et al: New response evaluation criteria in solid tumours: Revised RECIST guideline (version 1.1). Eur J Cancer 45: 228-247, 2009.

16. Rikova K, Guo A, Zeng Q, Possemato A, Yu J, Haack H, Nardone J, Lee K, Reeves C, Li Y, et al: Global survey of phosphotyrosine signaling identifies oncogenic kinases in lung cancer. Cell 131: 1190-1203, 2007.

17. Rimkunas VM, Crosby KE, Li D, Hu Y, Kelly ME, Gu TL, Mack JS, Silver MR, Zhou X and Haack H: Analysis of receptor tyrosine kinase ROS1-positive tumors in non-small cell lung cancer: Identification of a FIG-ROS1 fusion. Clin Cancer Res 18: 4449-4457, 2012.

18. Chen YF, Hsieh MS, Wu SG, Chang YL, Shih JY, Liu YN, Tsai MF, Tsai TH, Yu CJ, Yang JC and Yang PC: Clinical and the prognostic characteristics of lung adenocarcinoma patients with ROS1 fusion in comparison with other driver mutations in East Asian populations. J Thorac Oncol 9: 1171-1179, 2014.

19. Wu S, Wang J, Zhou L, Su D, Liu Y, Liang X, Zhang S and Zeng X: Clinicopathological characteristics and outcomes of ROS1-rearranged patients with lung adenocarcinoma without EGFR, KRAS mutations and ALK rearrangements. Thorac Cancer 6: 413-420, 2015.

20. Takeuchi K, Soda M, Togashi Y, Suzuki R, Sakata S, Hatano S, Asaka R, Hamanaka W, Ninomiya H, Uehara H, et al: RET, ROS1 and ALK fusions in lung cancer. Nat Med 18: 378-381, 2012.

21. Mescam-Mancini L, Lantuéjoul S, Moro-Sibilot D, Rouquette I, Souquet PJ, Audigier-Valette C, Sabourin JC, Decroisette C, Sakhri L, Brambilla E and McLeer-Florin A: On the relevance of a testing algorithm for the detection of ROS1-rearranged lung adenocarcinomas. Lung Cancer 83: 168-173, 2014.

22. Song Z, Zheng Y, Wang X, Su H, Zhang Y and Song Y: ALK and ROS1 rearrangements, coexistence and treatment in epidermal growth factor receptor-wild type lung adenocarcinoma: A multicenter study of 732 cases. J Thorac Dis 9: 3919-3926, 2017.

23. Zhu YC, Liao XH, Wang WX, Xu CW, Zhuang W, Wei JG and Du KQ: Dual drive coexistence of EML4-ALK and TPM3-ROS1 fusion in advanced lung adenocarcinoma. Thorac Cancer 9: 324-327, 2018. 
24. Zhu YC, Lin XP, Li XF, Wu LX, Chen HF, Wang WX, Xu CW, Shen JF, Wei JG and Du KQ: Concurrent ROS1 gene rearrangement and KRAS mutation in lung adenocarcinoma: A case report and literature review. Thorac Cancer 9: 159-163, 2018.

25. Zhu YC, Xu CW, Ye XQ, Yin MX, Zhang JX, Du KQ, Zhang ZH and $\mathrm{Hu} \mathrm{J}$ : Lung cancer with concurrent EGFR mutation and ROS1 rearrangement: A case report and review of the literature. Onco Targets Ther 9: 4301-4305, 2016.

26. Uguen A, Schick U and Quéré G: A rare case of ROS1 and ALK double rearranged non-small cell lung cancer. J Thorac Oncol 12: e71-e72, 2017.

27. Pan W, Yang Y, Zhu H, Zhang Y, Zhou R and Sun X: KRAS mutation is a weak, but valid predictor for poor prognosis and treatment outcomes in NSCLC: A meta-analysis of 41 studies. Oncotarget 7: 8373-8388, 2016.

28. Zhou J, Mo W, Zhao J, Zheng J, Ding W and Zhou J: Clinicopathological features associated with EGFR gene mutation in non-small cell lung cancer patients. Zhonghua Yi Xue Za Zhi 94: 2332-2336, 2014 (In Chinese)

29. Cai W, Li X, Su C, Fan L, Zheng L, Fei K, Zhou C, Manegold C and Schmid-Bindert G: ROS1 fusions in Chinese patients with non-small-cell lung cancer. Ann Oncol 24: 1822-1827, 2013.

30. Zhang L, Jiang T, Zhao C, Li W, Li X, Zhao S, Liu X, Jia Y, Yang H, Ren S and Zhou C: Efficacy of crizotinib and pemetrexed-based chemotherapy in Chinese NSCLC patients with ROS1 rearrangement. Oncotarget 7: 75145-75154, 2016.
31. Mok TS, Wu YL, Thongprasert S, Yang CH, Chu DT, Saijo N, Sunpaweravong P, Han B, Margono B, Ichinose Y, et al: Gefitinib or carboplatin-paclitaxel in pulmonary adenocarcinoma. N Engl J Med 361: 947-957, 2009.

32. Han JY, Kim SH, Lee YS, Lee SY, Hwang JA, Kim JY, Yoon SJ and Lee GK: Comparison of targeted next-generation sequencing with conventional sequencing for predicting the responsiveness to epidermal growth factor receptor-tyrosine kinase inhibitor (EGFR-TKI) therapy in never-smokers with lung adenocarcinoma. Lung Cancer 85: 161-167, 2014.

33. Lin JJ and Shaw AT: Recent advances in targeting ROS1 in lung cancer. J Thorac Oncol 12: 1611-1625, 2017.

34. Pekar-Zlotin M, Hirsch FR, Soussan-Gutman L, Ilouze M, Dvir A, Boyle T, Wynes M, Miller VA, Lipson D, Palmer GA, et al: Fluorescence in situ hybridization, immunohistochemistry, and next-generation sequencing for detection of EML4-ALK rearrangement in lung cancer. Oncologist 20: 316-322, 2015

35. Wu YL, Yang JC, Kim DW, Lu S, Zhou J, Seto T, Yang JJ, Yamamoto N, Ahn MJ, Takahashi T, et al: Phase II study of crizotinib in East asian patients with ROS1-positive advanced non-small-cell lung cancer. J Clin Oncol 36: 1405-1411, 2018.

36. Song A, Kim TM, Kim DW, Kim S, Keam B, Lee SH and Heo DS: Molecular changes associated with acquired resistance to crizotinib in ROS1-rearranged non-small cell lung cancer. Clin Cancer Res 21: 2379-2387, 2015. 